\title{
MANUEL LÁZARO PULIDO, FRANCISCO LEÓN FLORIDO, ESTÍBALIZ MONTORO MONTERO (eds.), Pensar la Edad Media cristiana: la presencia de la teología medieval en el pensamiento moderno, Madrid, Sindéresis, 2018, 425 pp., ISBN: $\mathbf{9 7 8 8 4 1 6 2 6 2 0 6 9}$
}

Reseñado por DAVID ARBESÚ, University of South Florida arbesu@usf.edu

Este nuevo volumen de la Colección Biblioteca de Humanidades Salmanticensis (Serie Filosofía) es el segundo de una serie de libros sobre filosofía medieval cuyo título comienza por Pensar la Edad Media cristiana. El primero de ellos, aparecido en 2016 y en el que colaboraron también como editores M. Lázaro Pulido y F. León Florido, estuvo dedicado a La querella del imperio y el pensamiento político XIV-XV (y otros estudios). Dichas publicaciones están adscritas al equipo de investigación sobre «Filosofía y teología en la Europa de la Edad Media: Atenas, Córdoba, París» de la Universidad Complutense de Madrid, grupo cuya actividad es tan fructífera que ya se han proyectado los que serán los dos siguientes volúmenes de la serie: uno dedicado a San Buenaventura de Bagnoregio (12171274) y el siguiente a los Espacios de la filosofía medieval: Córdoba, Toledo, París. Como cabía esperar, pues, los dieciocho artículos recogidos aquí son el resultado de las presentaciones de sus autores en los Encuentros de Filosofía Medieval organizados por dicho grupo.

En la Introducción al volumen, firmada por sus tres editores, cabe distinguir la presentación del tema general del libro - «el objetivo propuesto a los investigadores es el de ... reflexionar sobre las ideas y doctrinas teológicas medievales que han servido de tránsito desde la Edad Media a la Modernidad» (p. 10) - y el resumen de cada uno de los dieciocho artículos que lo componen. El objetivo y mínimo común denominador de estos trabajos es, pues, el hecho de que todos «muestran la vitalidad del pensamiento filosóficoteológico de la Edad Media y su significación en la construcción de la Modernidad» (p.14), o, en otras palabras, que vienen a establecer que no ha habido tanta refutación del pensamiento medieval como a menudo se cree y que las ideas maceradas en la Edad Media han servido de puente al futuro. Esta máxima es aplicable a la práctica totalidad de los trabajos aquí presentes, que por lo general orientan su temática a este puente entre épocas, aunque - como es lógico - en un volumen con tantas contribuciones hay de todo, y en algunos esta conexión es mucho más evidente que en otros.

Un buen ejemplo del espíritu general del volumen es el primero de los artículos, firmado por uno de los editores del volumen, León Florido, que conecta perfectamente con lo dicho en la Introducción y que versa sobre la presencia de la teología crítica escolástica en el racionalismo moderno, sobre todo al incidir en una cuestión sabida pero pocas veces desarrollada. Si bien es lícito considerar a René Descartes (1596-1650) el fundador del pensamiento moderno, no lo es menos el hecho de que su ruptura con el saber tradicional no fue tan brusca como en general se considera. Así, basándose en tres estructuras conceptuales básicas, la distinción formal ex natura rei, la doctrina del ser objetivo (esse objectivum) y la hipótesis del poder absoluto de Dios (de potentia absoluta Dei), 
León Florido hace un recorrido por estas estructuras que vuelve la vista atrás a Santo Tomás de Aquino (1225-1274) y concluye con el cumplimiento moderno de esas estructuras subyacentes con la filosofía de Immanuel Kant (1724-1804) para demostrar, así, que las diversas vías que conducen al escepticismo moderno tienen su origen en la crisis de la teología tradicional.

Un planteamiento similar tiene otro contundente artículo de J. C. Utrera García, quien cuestiona ahora la pretendida ruptura de Martín Lutero (1483-1546) con el pasado y demuestra que, al contrario, todo su pensamiento religioso y político, lejos de apartarse de la teología voluntarista, más bien la consuma. El puente entre dos épocas muy distintas es evidente, por ejemplo, en el artículo de F. Bertelloni sobre el casus imminens descrito en la obra De eclesiastica sive summi pontificis potestate (1301) de uno de los discípulos más aventajados de Santo Tomás en París, Egidio Romano (1247-1316), y el concepto de Ausnahmezustand del politólogo y filósofo alemán Carl Schmitt (1888-1985), estableciendo así una muy apropiada conexión entre dos conceptos desarrollados en siglos tan dispares como el XIII y el XX y que, sin embargo, pueden considerarse de manera conjunta. También así el trabajo de V. Llamas Roig sobre el método fenomenológico de Edmund Husserl (1859-1938), preceptor de la tradición filosófica continental, que viene a incidir en la influencia de la filosofía medieval sobre la contemporánea, o el de I. Verdú Berganza, quien analiza magistralmente la presencia del pensamiento del franciscano Thomas Bradwardine, sobre todo la desarrollada en su obra De causa Dei et de virtute causarum, en la filosofía de los siglos XVI al XVIII.

Siguiendo en la misma línea, el trabajo de M. González Fernández analiza la obra de Giordano Bruno (1548-1600) en cuanto se constituye como diálogo con Juan Duns Scoto (1266-1308), aunque sea para polemizar con él, acercamiento que comparte con el artículo de R. Lázaro Centero sobre el diálogo entre Michel de Montaigne (1533-1592) y el filósofo barcelonés Ramón Sibiuda (1385-1436). Con un sugestivo título, M. I. Zorroza Huarte diserta sobre los «Orígenes teológicos de la noción moderna de propiedad» y V. Fernández Polanco hace un repaso - de carácter más historiográfico - por la obra del investigador suizo André de Muralt (1931-) sobre el pensamiento de la filosofía medieval.

Algunos trabajos están más centrados en un solo concepto o época concreta. M. Cabré Durán analiza con acierto la influencia en la medicina moderna de Arnau de Vilanova (ca. 1240-1311), médico y teólogo valenciano acusado de herejía y condenado por la Universidad de París, aunque en puridad el artículo se centra en la popularidad de sus obras durante el Renacimiento. M. Lázaro Pulido, otro de los editores del volumen, analiza la influencia de las ideas apocalípticas del Nuevo Testamento en la obra Apocalypsis nova de Amadeo de Silva (1420-1482) a través del calabrés Joaquín de Fiore (1135-1202), centrando la pieza en torno a los «mundos emergentes» en Europa y América tras el descubrimiento del Nuevo Mundo y la Reforma Protestante. E. Lacca diserta sobre la recepción de la escolástica medieval por los filósofos y teólogos de la Escuela de Salamanca, en concreto por los escritores Juan Sánchez Sedeño (1552-1615) y Diego de Zúñiga (1536-1597), M. Beltrán centra su contribución en la figura de Abraham Cohen de Herrera (1570-1635), haciendo guiños a la filosofía de Duns Scoto y Tomás de Aquino, y C. Díaz de Rábago firma

Revista Española de Filosofía Medieval, 26/1 (2019), ISSN: 1133-0902, pp. 155-175 
un trabajo en el que se analiza cómo la física moderna ha llegado, por caminos distintos, a las mismas conclusiones respecto a la materia que los filósofos medievales (la negación de la materia como entidad), aunque le falta algo de espacio para ahondar en sus explicaciones.

Por último, hay un grupo de artículos algo más breves y centrados en un único autor. C. Teleanu aporta su granito de arena con un artículo sobre la obra de Ramón Llull (12321316), A. Aparicio Marcos hace lo propio con Guillermo de Ockham (1285-1347), M. Méndez Alonzo con el florentino Francesco Guicciardini (1483-1540) y G. Colacicco con el teólogo Francisco Suárez (1548-1617).

El objetivo del volumen se cumple con creces. Impresiona ver la cantidad de autores y temas tratados en sus más de cuatrocientas páginas, sobre todo teniendo como guía un tema tan complicado (e interesante) como la continuación del pensamiento medieval en la época moderna. En este sentido hay que advertir, como ya se habrá comprobado, que el término «modernidad» se entiende aquí en un sentido muy amplio, es decir, se construye sin límite de tiempo en oposición a la Edad Media o - mejor - a ese período de «dos mil años de estabilidad filosófica propiciada por la conservación de la estructura conceptual greco-cristiana» (p. 27). Así, mientras que algunos artículos están centrados en una única época, en otros se establecen puentes entre autores de siglos consecutivos y en otros se hace un recorrido que va desde el siglo XII hasta nuestros días.

Por lo general bien editado, se echa en falta algo más de revisión por parte del equipo editorial. Como es habitual en este tipo de volúmenes hay ciertas incoherencias que podrían haberse evitado fácilmente (uno de los artículos está en francés, frente a los otros diecisiete en castellano), hay erratas importantes - como al inicio del artículo de Díaz de Rábago, donde se repiten las dos primeras líneas (p. 45) -, algunos párrafos de autores cuya lengua materna no es el español son bastante complicados de entender, y en los resúmenes de la Introducción pasamos de la tercera a la primera persona, evidenciando así que han sido escritos por los propios autores y después más o menos editados por el equipo editorial. De manera más importante, sobre todo en este tipo de libro hubiera sido muy deseable un índice onomástico y temático, aunque solo sea por facilitar la consulta de la riqueza y variedad de temas tratados en sus páginas.

Con todo, La presencia de la teología medieval en el pensamiento moderno es un interesante (y muy recomendable) volumen que será de utilidad a todos los interesados en el campo. No se equivocan los editores cuando recalcan la necesidad de este tipo de estudios. Los primeros intelectuales modernos, como bien se afirma en el libro, intentaron borrar en su producción «las huellas de un pasado que han denunciado por su clericalismo y oscuridad» (p. 10), con lo que es necesario profundizar en sus ideas para demostrar que, en la mayoría de ellos, no hay ruptura, sino continuidad con el pensamiento filosófico medieval. 